\title{
Isolation and antimicrobial susceptibility pattern of Escherichia Coli from laying chicken and egg in Jimma Town, Ethiopia
}

Diriba Taddese ( $\nabla$ dirrooballee@gmail.com )

Jimma University College of Agriculture and Veterinary Medicine

Eshetu Shumi

jima university college of agriculture and veterinary medicine

Mestewot Asefa

jimma university college of agriculture and veterinary medicine

\section{Research}

Keywords: Antimicrobial, E. coli, egg, farm, market

Posted Date: January 23rd, 2020

DOI: https://doi.org/10.21203/rs.2.21745/v1

License: (c) (i) This work is licensed under a Creative Commons Attribution 4.0 International License.

Read Full License 


\section{Abstract}

\section{Objectives}

Food borne diseases are one of the main important issues in the world. Escherichia coli are considered as the most prevalent food borne pathogen. A cross sectional study was conducted from January 6- 2018 to September 10-2019 on cloacae swab; farm and market's egg at Jimma town to isolate, identify and determine antimicrobial susceptibility patterns.

Result

Out of 415 total samples, 156 (37.59\%) were identified as E. coli from farm eggshell 21/83 $(25.30 \%)$, farm egg content 12/83 (14.46\%), cloacae swab 42/83 (50.60\%) and market egg shell 45/83 (54.23\%). In the current study antimicrobial susceptibility test of $E$. coli isolates from different sample types revealed varying degree of susceptibility to antimicrobial. Isolated $E$. coli was highly susceptible to Ciprofloxacin $(100 \%)$, Gentamicine (100\%), Streptomycin ( $96.4 \%)$, sulfonamides (94\%), Kanamycin (91\%), Chloramphenicol ( $89.5 \%$ ) , tetraccine (78.9\%), Trimethoprim (75\%) these are considered appropriate for empirical treatment of $E$. coli in the study area. Moreover, resistance of isolates with $100 \%, 75 \% 50 \%, 25 \%$, $1.6 \%$ and $0.5 \%$ was developed to ampicillin, neomycin, cefoxitin oxytetracycline, Streptomycin and tetraccine respectively. The presence of E.coli within egg/and chicken can pose serious public health problems. The appropriate hygienic practices of eggs at both farms and markets should be under taken.

\section{Introduction}

Poultry feeds are food materials used in raising poultry birds. Poultry feeds are referred to as complete feeds as they are designed to contain all the nutritional materials in the form of meat and egg production these have significant importance in humane food [1]. Advances in science and technology have widely contributed for the expansion of the poultry industry and a number of strategies have been adopted to modulate the quality of poultry products like egg and meat[2]. Escherichia coli (E. coli) are major factors for declining of food quality including food originated from poultry due to poultry and poultry products being a primary source of bacterial infection. It has most often been associated with the consumption of contaminated foods of animal origin, such as poultry, swine, dairy products and eggs [3].

Most of E. coli isolates are harmless; however, some strains are pathogenic and may cause serious food poisoning in human beings [4]. In the past two decades, severe outbreaks with gas- trointestinal symptoms have occurred by food borne pathogenic E. coli, particularly 0157:H7 [5]. E. coli and its related species are named as "enteric bacteria"; because they mostly live in the intestinal tracts of human and other animal species [6]. Moreover E.coli is one of foods borne bacteria and resistant to one or more antimicrobial drugs used in medicine and agriculture. Antibiotic resistance in E. coli is of particular concern because it is the most common gram-negative pathogen in humans[7]. Some global epidemics have also been linked with egg consumption and known to cause egg-borne pathogens present in poultry 
eggs and their contents. Food poisoning are associated with egg- borne pathogens may cause severe morbidity or mortality period with diarrhea, vomiting, nausea and abdominal cramps[4].

In the previous study, which carried out the determination of isolation and antimicrobial drug resistance patterns of E. coli isolates and estimates, the level of the pathogen was connected at eastern Ethiopia on poultry farm of cloacae swabs sample and in different studies were conducted on the prevalence of E.coli from both markets and farm egg[8]. There is very little information regarding the E.coli profile from egg and cloacae of poultry and drug susceptibility patterns particularly in Jimma Town, south western Ethiopia. Therefore, this study was aimed to isolate E.coli from cloacae swabs, mark and farm egg and, asses the antimicrobial susceptibility patterns of the isolates.

\section{Materials And Methods}

\section{Description of the Study Area}

The study was conducted on market egg, farm and cloacae swabs of laying chicken in Jimma town, Oromia regional state, Southwestern Ethiopia.

Study Design

A cross-sectional study was conducted from January, 2018 to November, 2018 to isolate, identify and characterize antimicrobial susceptibility patterns of E.coli species from market egg, farm egg and cloacae swabs of laying chicken in Jimma town.

Sample collecting and processing

A total of 166 samples of egg were collected (83 samples of egg from market and 83 samples of egg from farm to maintain proportionality) were collected and again 83 cloacae swabs were collected from chicken these laid sample of egg at farm.

Of 83 samples of egg from Jimma town poultry farms; 16, 58, 6 and 3 samples of egg and cloacae swab of laying samples of egg were collected randomly after clustering samples for sample sours farm that include Jimma University College of Agriculture and Veterinary Medicine, Jimma University Kito Furdisa Development Enterprise, Emabet and Daniel poultry farm respectively. Eggs were collected in sterile bags as soon as egg laid using sterile glove and transported to the laboratory and cloacae swabs from these laying sample of eggs were collected and swabs were placed in sterile tube contain $10 \mathrm{ml}$ peptone water. Eighty three egg sellers were selected randomly from Jimma town markets randomly and Single egg from each egg seller were collected in sterile bags randomly using sterile glove.

Cloacae swabs were incubated at $37^{\circ} \mathrm{C}$ for $24 \mathrm{~h}$ as soon as samples were collected. Samples of egg were processed according to (Loongyai et at., 2011) in which external shell of eggs were swab with sterile cotton swabs dipped in sterile peptone broth and placed in $10 \mathrm{ml}$ of peptone broth and subsequently incubated for $24 \mathrm{~h}$ at $37^{\circ} \mathrm{C}$. In order to collect the egg contents, eggs were surface sterilized by immersion 
in $75 \%$ alcohol for $2 \mathrm{~min}$, air dried in a sterile chamber for $10 \mathrm{~min}$, then cracked with a sterile knife. Each egg's content was mixed thoroughly and $1 \mathrm{ml}$ of the mixed egg content was inoculated into $9 \mathrm{ml}$ of peptone broth and incubated at $37 \mathrm{C}$ for $24 \mathrm{~h}$.

Isolation and identification of E. coli

A loop from incubated peptone water of egg shells swabbed cloacae swabs and egg content were streaked on MacConkey agar and incubated for $24 \mathrm{hr}$ at $37^{\circ} \mathrm{C}$. Colonies on MacConkey agar having bright pink-red via lactose fermentation were taken and streak on Eosin Methline Bleu (EMB) agar and plates were incubated for $24 \mathrm{hr}$ at $37^{\circ} \mathrm{C}$. Then the plates were examined for the presence of colonies that may resemble E.coli according to the technique recommended by [9]. The organisms showing characteristic colony morphology of E. coli on EMB agar having black golden on the center of colonies were isolated (finger1). Isolated colonies were taken directly from the plate and transferred to nutrient agar for farther identification of E.coli with biochemical test.

Isolated E. coli suspected colonies were biochemically identified according to (Dean et at., 1972) in which Catalase positive, Citrate negative, Indole Positive, Motile, Methyl Red (MR) positive, yellow at both slant and bottom, gas formed and negative for the formation of $\mathrm{H}_{2} \mathrm{~S}$ on Triple Sugar Iron Agar (TSIA) test and Voges Proskauer (VP) E. coli colony were identified(finger 2).

Antimicrobial Susceptibility Patterns of isolated E. Coli

Identified E. coli with biochemical test were taken for antimicrobial patters with sub culturing on nutrient agar medium. Twelve (12) antimicrobial discs of clinically utilizing drug were applied for each isolates with qualitative agar diffusion method (Kirby-Bauer method) by employing Mueller Hinton agar medium [10] (finger 3). Culture of each isolated were compared with 0.5 McFarland turbidity standards. Isolates were swabbed on mueller-hinton agar using sterile swabs.

Antimicrobial impregnated discs were seated on the surface of cultures of Muller-Hinton agar and incubate at $37^{\circ} \mathrm{C}$ for $20 \mathrm{~h}$ intended for $\mathrm{E}$. coli isolates taste for susceptibility to the antimicrobial using the disk diffusion method according to guidelines set by the clinical laboratory standards institute (CLSI) [11]. For each antimicrobial, $\mathrm{mm}$ of inhibition zone was measured by using digital vernier calipers and inhibition zone of each antimicrobial were classified (resistant, intermediate, or susceptible).

\section{Results}

Prevalence of E. coli from farm egg, cloacae swab and market egg

Out of 415 total samples, 156 (37.59\%) were identified as E. coli from farm eggshell $(n=83)$, farm egg content $(n=83)$, cloacae swab $(n=83)$, market egg shell $(n=83)$ and market egg contents $(n=83)$ with rate of $21(25.3 \%), 12(14.46 \%), 42(50.6 \%), 45$ (54.23\%) respectively, were identified (Table 1).

Table 1. Identified E. coli from farm egg, cloacae Swab and Market Egg Samples 
Sample Source Type of Sample Number of Examined Identified E. coli (\%)
Egg shell
83
$21(25.3 \%)$

Jimma Town

Poultry Farm Egg content

83

$12(14.46 \%)$

Cloacae Swabs

83

$42(50.6 \%)$

Jimma Town Egg shell

83

$45(54.23 \%)$

Market

egg content

83

$36(43.37)$

Total

415

$156(37.59 \%)$

Antimicrobial susceptibility pattern

The result of antimicrobial susceptibility test of E. coli isolated subjected to 12 selected antimicrobial agents are shown in Table 2. The current study on antimicrobial susceptibility test of E. coli recovered from different sample types revealed a varying degree of susceptibility to antimicrobial agents tested. $E$. coli was highly susceptible to Kanamycin (91\%), Chloramphenicol (89.5\%), Ciprofloxacin (100\%), Streptomycin (96.4\%), Tetraccine (78.9\%), Sulfonamides (94\%), Gentamicine (100\%), Trimethoprim (75\%). Furthermore, resistance of $100 \%, 75 \% 50 \%, 25 \%, 1.6$ and 0.5 was developed to Ampicillin, Neomycin, Cefoxitin Oxytetracycline, Streptomycin and Tetraccine respectively. 
Table 2

Antimicrobial susceptibility test result of E. coli isolates

\begin{tabular}{|c|c|c|c|c|}
\hline \multirow[t]{2}{*}{$\begin{array}{l}\text { Antimicrobial } \\
\text { Agent }\end{array}$} & \multirow{2}{*}{$\begin{array}{l}\text { Disk } \\
\text { Concentration } \\
(\mu g)\end{array}$} & \multicolumn{3}{|c|}{$\begin{array}{l}\text { Susceptible, Intermediate and Resistance Pattern of E. coli } \\
\text { 0157:H7 Isolates }\end{array}$} \\
\hline & & S\% & $\mathrm{R} \%$ & $1 \%$ \\
\hline KA & 30 & 91.0 & 0.0 & 9.0 \\
\hline W-5 & 5 & 75.0 & 0.0 & 25.0 \\
\hline $\mathrm{CHL}$ & 30 & 89.5 & 0.0 & 10.5 \\
\hline CPR & 5 & 100.0 & 0.0 & 0.0 \\
\hline STR & 10 & 96.4 & 1.6 & 2.0 \\
\hline TTC & 30 & 78.9 & 0.5 & 20.6 \\
\hline S3 & 0.3 & 94.0 & 0.0 & 16.0 \\
\hline Gent & 10 & 100.0 & 0.0 & 0.0 \\
\hline $\mathrm{NeO}$ & 30 & 0.0 & 75.0 & 25.0 \\
\hline Amp & 10 & 0.0 & 100.0 & 0.0 \\
\hline Cfx & 30 & 0.0 & 50.0 & 50.0 \\
\hline NA & 30 & & 25.0 & 75.0 \\
\hline
\end{tabular}

Foot notes: - Cfx: cefoxitin, Gent; Gentamicine, KAN: Kanamicine, STR: Stryptomycin, CPR: Ciprofloxacin Neo: Neomycine, Chl: Chloromphenicol, S3: Sulfonamides, W: Trimethophorim, TE: Tetracycline, AMP: Ampicilline, NA: Oxytetracycline, S: susceptible, R: resistance, I: Intermediate

\section{Discussion}

The present study was conducted to isolate, identify and determine antimicrobial susceptibility patterns of E. coli from farm egg, cloacae swab and market egg samples in Jimma town. Food borne diseases is one of the important issues worldwide. E. coli is considered the most prevalent food borne pathogen that has gained increased attention in recent years. In the present the prevalence of E. coli from egg is in line with the study of Germini et al., 2009. But this finding is lower than some reports from previous works (13). The prevalence of E. coli from cloacae in this study is in line with the privies studies[14, 15]. In contrast the finding of this prevalence in the present study is higher than the study of $[16,22,23,24]$ in which E. coli was isolated from cloacae samples taken from poultry farms. In another study, [25, 26] E. coli was isolated from faeces of poultry sample at different farms in Nigeria that may shows contamination of cloacae of chicken. Observed variation in prevalence among studies could be attributed 
to differences in sampling and isolation procedures, used culture, fecal contact to egg, hygienic condition of poultry house, study design and season variation in which samples are collected [17].

In the present study, all of the E. coli isolates were susceptible to Kanamycin, Trimethoprim, Ciprofloxacin and Chloramphenicol is in line with the work of Hiko et al ., 2008. However, the study of Zhao et al., 2005 revealed that there was resistant strain to the drugs such as Tetracycline, Kanamycine, Trimethoprim, Ciprofloxacin and Chloramphenicol. On the other side, the current study revealed that all isolates were resistant to Ampicilin which has similarity with finding of Reuben and Owuna, (2013). In this study 39 $(25 \%)$ isolates out of 156 have multiple drug resistance having comparable related with previous findings [19]. This variation is probably attributed to the expression of resistant gene code by the pathogen which associated with emerging and re-emerging aspects of the isolates [21].

\section{Conclusion}

The present study shows a substantial presence of $E$. coli farm egg, cloacae swab and market egg samples in the town. In this study, the overall prevalence of $E$. coli that contaminates the market egg shell was higher that may show contamination is avail in the market than farm. Though most of the E. coli isolates subjected to antimicrobial susceptibility tests show different degrees of resistance against the antimicrobial discs tested. The isolated bacteria were susceptible to most of the drugs used, those important for the treatment and multi drug resistance occurred in $25 \%$ of isolates for in vitro tested in this study.

Based on the above conclusion the following recommendations were forwarded:

- Poultry farm should be trained to ensure the hygienic practices of poultry farm.

- Hygiene measures must be implemented on the market egg contamination to prevent the contamination of egg.

- In vitro drug sensitivity testing of coli should be performed so that proper treatments can be instituted for $E$. coli infected patients at animal and human health center.

- Further study on molecular characterization of both coli 0157:H7 and other shiga toxin producing $E$. coli strains should be conducted.

Limitation

The isolates were not molecularly characterized due to the lack of resources.

\section{List Of Abbreviations}

EMB Eosin methylene blue

BPW Buffered pepton water 
TSIA Triple Sugar Iron Agar

VP Voges Proskauer negative

\section{Declarations}

Ethical Clearance and Consent to Participate

Ethical clearance was obtained from Jimma University, College of Agriculture and Veterinary Medicine. All participants were informed about the aim of research. Additionally, written consent was obtained from Jimma town administration office.

Consent to Publication

Not applicable

Availability of Data and Material

The data sets developed and analyzed during the current study are available from the first author or from the corresponding authors upon request.

Competing Interests

The authors declare that they have no competing interest.

Funding

Jimma University College of Agriculture and Veterinary Medicine was sponsored for the research to design the study and collection, analyzing, and interpretation of the data and writing of the manuscript.

Author's Contribution

D.T, E.S and M.A were participated in the conception of the research idea, Methodology, carried out the laboratory work, analyze the data and approve the manuscript.

Acknowledgements

I would like to extend my gratitude for Jimma University College of Agriculture and Veterinary Medicines for giving me the opportunity to pursue this study. Finally, I would like to extend my heartfelt thanks to all of my friends for their support in providing me necessary information and constructive comments during implementation of this study.

\section{References}


1. Chowdhury, A., Iqbal, A., Uddin, M.G. and Uddin, M., 2011. Study on Isolation and Identification of Salmonella and Escherichia coli from Different Poultry Feeds of Savar Region of Dhaka, Bangladesh. Journal of Scientific Research, 3(2), pp.403-411.

2. Silas, A.F., Ayorinde, A.O., Daisy, E., Mark, S.O., Bolante, O.O. and Nwakaegho, E.G., 2014. Effect of stocking density and quantitative feed restriction on growth performance, digestibility, haematological characteristics and cost of starting broiler chicks. Journal of Animal Health and Production, 2(4), pp.60-64

3. Loongyai, Wiriya, Benjamaporn Wiriya, and Naruemol Sangsawang. "Detection of Salmonella and Escherichia coli in egg shell and egg content from different housing systems for laying hens." International Journal of Poultry Science 10, no. 2 (2011): 93- 97.

4. Khan, A., Rind, R., Shoaib, M., Kamboh, A.A., Mughal, G.A., Lakho, S.A., Malhi, K.K., Nizamani, A.R. and Yousaf, A., 2016. Isolation, identification and antibiogram of Escherichia coli from table eggs. $J$. Anim. Health Prod, 4(1), pp.1-5.

5. Armstrong, G.L., Hollingsworth, J. and Morris Jr, J.G., 1996. Emerging foodborne pathogens: Escherichia coli 0157: $\mathrm{H7}$ as a model of entry of a new pathogen into the food supply of the developed world. Epidemiologic reviews, 18(1), pp.29-51.

6. Minnock, A., Vernon, D.I., Schofield, J., Griffiths, J., Parish, J.H. and Brown, S.B., 2000. Mechanism of Uptake of a Cationic Water-Soluble Pyridinium Zinc Phthalocyanine across the Outer Membrane ofEscherichia coli. Antimicrobial agents and chemotherapy, $\quad 44(3)$, pp.522-527.

7. Rasheed, M.U., Thajuddin, N., Ahamed, P., Teklemariam, Z. and Jamil, K., 2014. Antimicrobial drug resistance in strains of Escherichia coli isolated from food sources. Revista do Instituto de Medicina Tropical de São Paulo, 56(4), pp.341-346.

8. Shecho, M., Thomas, N., Kemal, J. and Muktar, Y., 2017. Cloacael carriage and multidrug resistance Escherichia coli 0157: H7 from poultry farms, eastern Ethiopia. Journal of veterinary medicine, 2017.

9. Germini, A., Masola, A., Carnevali, P. and Marchelli, R., 2009. Simultaneous detection of Escherichia coli 0175: H7, Salmonella spp., and Listeria monocytogenes by multiplex PCR. Food Control, 20(8), pp.733-738.

10. 10 Olana, M., 2018. Detection and Antimicrobial Susceptibility Test of sallmonella Species along Beet supply chain in Bishoftu Town (Doctoral dissertation)..

11. Clinical and Laboratory Standards Institute, 2009. Performance standards for antimicrobial susceptibility testing of anaerobic bacteria: informational supplement. Clinical and Laboratory Standards Institute (CLSI).

12. Salihu, M.D., Garba, B. and Isah, Y., 2015. Evaluation of microbial contents of table eggs at retail outlets in Sokoto metropolis, Nigeria. Sokoto Journal of Veterinary Sciences, 13(1), pp.22-28.

13. Ejeh, F.E., Lawan, F.A., Abdulsalam, H., Mamman, P.H. and Kwanashie, C.N., 2017. Multiple antimicrobial resistance of Escherichia coli and Salmonella species isolated from broilers and local chickens retailed along the roadside in Zaria, Nigeria. Sokoto Journal of Veterinary Sciences, 15(3), pp.45-53. 
14. Lupindu, A.M., 2017. Isolation and characterization of Escherichia coli from animals, humans, and environment.

15. Shecho, M., Thomas, N., Kemal, J. and Muktar, Y., 2017. Cloacael carriage and multidrug resistance Escherichia coli 0157: H7 from poultry farms, eastern Ethiopia. Journal of veterinary medicine, 2017.

16. Keller, R., Pedroso, M.Z., Ritchmann, R. and Silva, R.M., 1998. Occurrence of virulence- associated properties inEnterobacter cloacae. Infection and immunity, 66(2), pp.645-649.

17. 17 Chapman, P.A., Malo, A.C., Ellin, M., Ashton, R. and Harkin, M.A., 2001. Escherichia coli 0157 in cattle and sheep at slaughter, on beef and lamb carcasses and in raw beef and lamb products in South Yorkshire, UK. International journal of food microbiology, 64(1-2), pp.139-150.

18. Hiko, A., Asrat, D. and Zewde, G., 2008. Occurrence of Escherichia coli 0157: H7 in retail raw meat products in Ethiopia. The Journal of Infection in Developing Countries, 2(05), pp.389-393.

19. Zhao, S., Maurer, J.J., Hubert, S., De Villena, J.F., McDermott, P.F., Meng, J., Ayers, S., English, L. and White, D.G., 2005. Antimicrobial susceptibility and molecular characterization of avian pathogenic Escherichia coli isolates. Veterinary microbiology, 107(3-4), pp.215-224.

20. Mora, A., Blanco, J.E., Blanco, M., Alonso, M.P., Dhabi, G., Echeita, A., González, E.A., Bernárdez, M.I. and Blanco, J., 2005. Antimicrobial resistance of Shiga toxin (verotoxin)-producing Escherichia coli 0157: H7 and non-0157 strains isolated from humans, cattle, sheep and food in Spain. Research in microbiology, 156(7), pp.793-806.

21. Reuben, R.C. and Owuna, G., 2013. Antimicrobial resistance patterns of Escherichia Coli 0157: H7 from Nigerian fermented milk samples in Nasarawa State, Nigeria. International Journal of Pharmaceutical Science Invention, 2(3), pp.38-44.

22. Olatoye, I.O., Amosun, E.A. and Ogundipe, G.A.T., 2012. Multidrug-resistant Escherichia coli 0157 contamination of beef and chicken in municipal abattoirs of southwest Nigeria. Nature and Science, 10(8), pp.125-132.

23. Chapman, P.A., Malo, A.C., Ellin, M., Ashton, R. and Harkin, M.A., 2001. Escherichia coli 0157 in cattle and sheep at slaughter, on beef and lamb carcasses and in raw beef and lamb products in South Yorkshire, UK. International journal of food microbiology, 64(1-2), pp.139-150.

24. Abong'o, B.O. and Momba, M.N., 2009. Prevalence and characterization of Escherichia coli 0157: H7 isolates from meat and meat products sold in Amathole District, Eastern Cape Province of South Africa. Food microbiology, 26(2), pp.173-176.

25. Ojo, O.E., Oyekunle, M.A., Ogunleye, A.O. and Otesile, E.B., 2009. E. coli 0157: H7 in food animals in part of S/Western Nigeria: Prevalence and in vitro antimicrobial susceptibility. Tropical Veterinarian, 26, pp.23-30.

26. Odugbemia, T., 2007. Multidrug resistance in E. coli 0157 strains and the public health implication. Science, 3(3), pp.22-33.

\section{Figures}



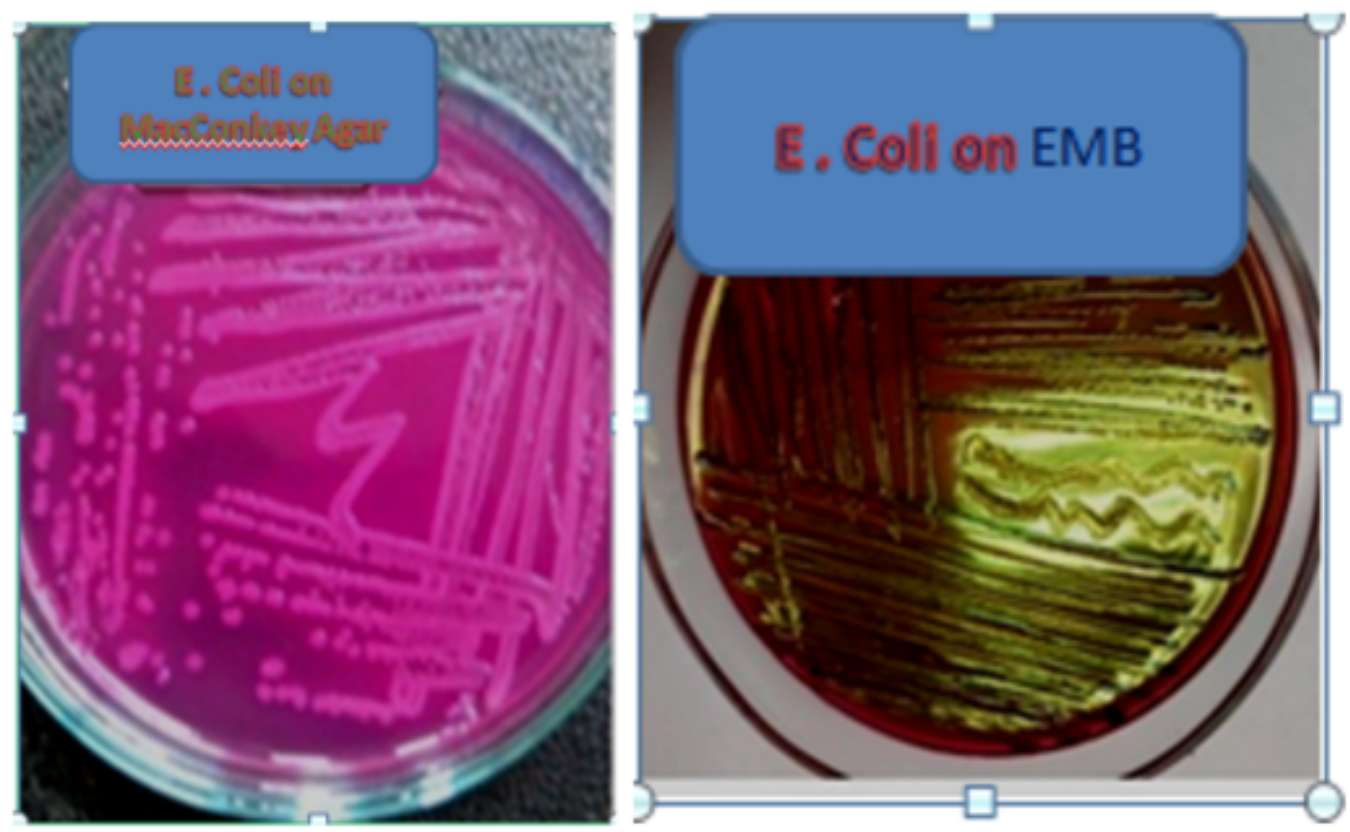

Figure 1

Red to Pink color on Mack Conckey and green metallic sheen on EMB from left to right

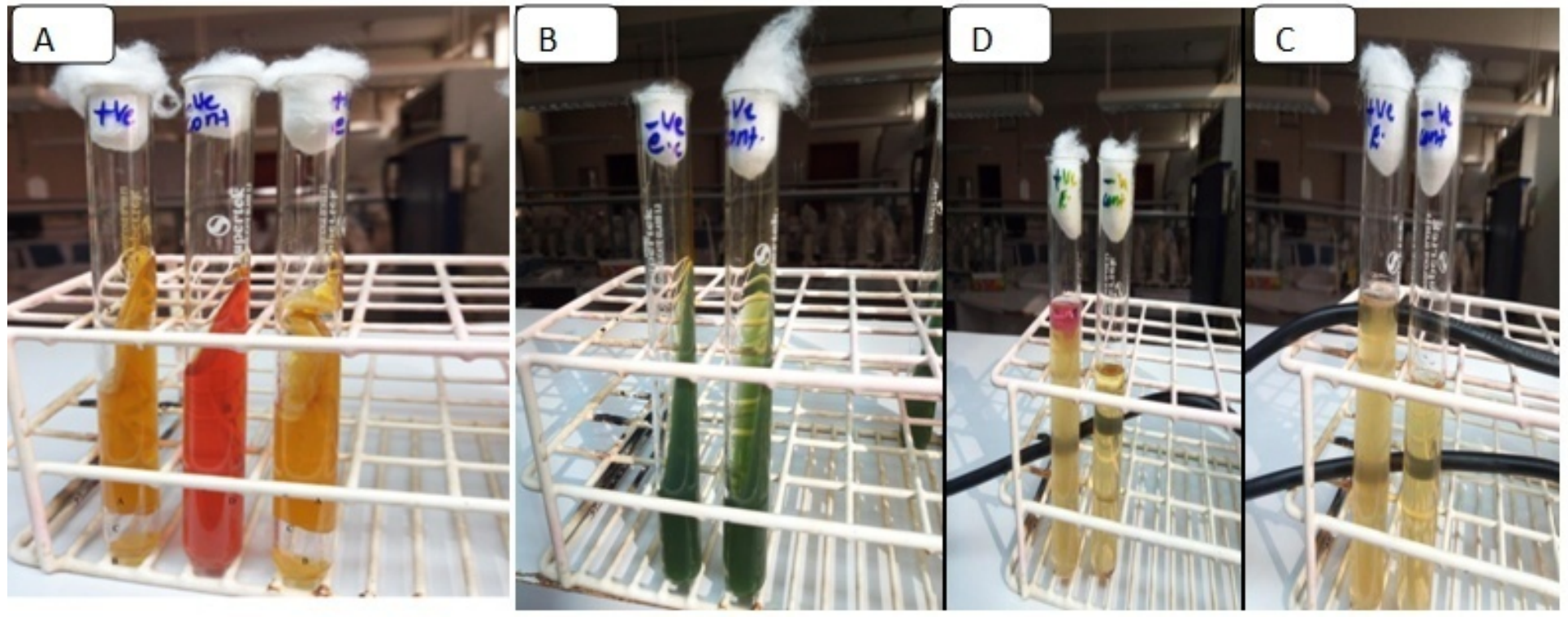

Figure 2

Biochemical characteristics of isolated Escherichia coli A: Triple sugar iron test, B: Citrate test C: Indole production test D: Motility test. 


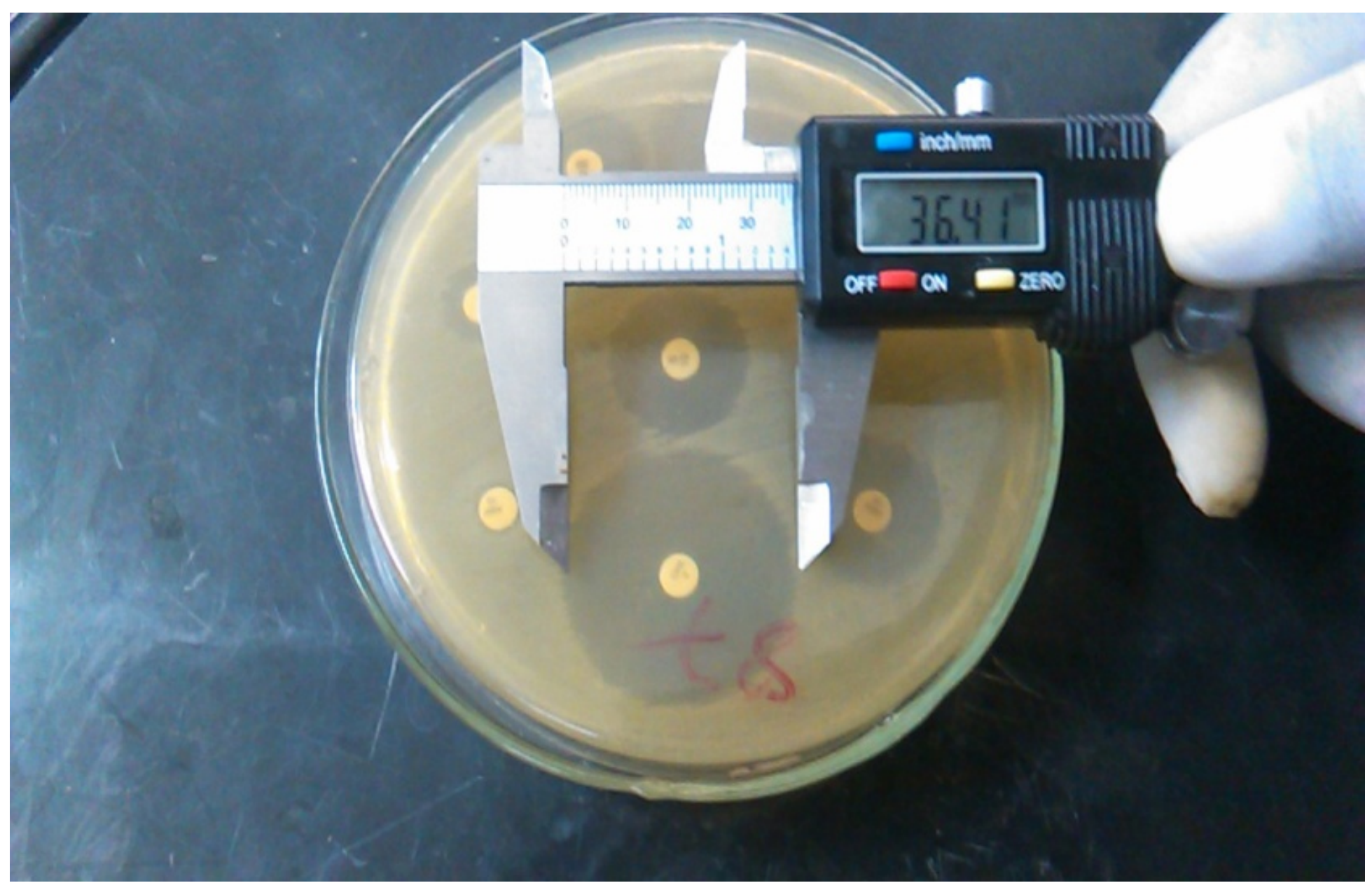

\section{Figure 3}

measuring antimicrobial disk diffusion susceptibility test for Escherichia coli isolates 